Full Length Article

\title{
The influence of ethanol-diesel blend on pollutant emissions from different bus fleets under acceleration transitions
}

\author{
Carmen Mata ${ }^{\mathrm{a}, *}$, Arántzazu Gómez ${ }^{\mathrm{b}}$, Octavio Armas ${ }^{\mathrm{b}}$ \\ a Universidad de Castilla-La Mancha, Campus de Excelencia Internacional en Energía y Medioambiente, Escuela de Ingeniería Minera e Industrial de Almadén, Plaza \\ Manuel Meca, 1, 13400 Almadén, Spain \\ ${ }^{\mathrm{b}}$ Universidad de Castilla-La Mancha, Campus de Excelencia Internacional en Energía y Medioambiente, Escuela de Ingeniería Industrial de Toledo, Campus Tecnológico \\ Real Fábrica de Armas, Av. Carlos III, s/n 45071 Toledo, Spain
}

\section{A R T I C L E I N F O}

\section{Keywords:}

On-road emissions

$\mathrm{NO}_{\mathrm{x}}$ emissions

Particle size distributions

PMP

Urban bus

Bioethanol

\begin{abstract}
A B S T R A C T
Main pollutant emissions produced by urban diesel buses are nitrogen oxides and particulate matter. Moreover, it is well known that level of emissions produced under real world driving conditions can be very different compared to those obtained under dyno-chassis tests or engine tests. The causes of these differences can be due to several sources such as operating conditions at various temperatures and pressures, different ground roughness, slopes, driver effect, change of gears or traffic. This work studies the effect of two different fuels on nitrogen oxides and particle size distributions under real world driving sequences of vehicle acceleration. Fuels tested were a low sulfur Diesel fuel (without biodiesel) and a binary ethanol-diesel fuel blend. This work was done with two models of similar buses, each one operating in cities located at different altitudes. Results show a reduction in particle concentration when ethanol-diesel blend was used. Mean geometric diameters decreased when ethanol-diesel was used. Concerning nitrogen oxides emissions, different trends were observed between vehicles depending on the transient sequence and the fuel used. Ethanol-diesel fuel blend reduces $\mathrm{NO}_{\mathrm{x}}$ at high altitude, but increases at low altitude. All results were probably affected by the altitude of the cities more than by the vehicle model itself.
\end{abstract}

\section{Introduction}

Pollutant emissions produced by urban buses constitute an important part of air pollutants in a city [1]. Although currently, a great percentage of these vehicles use more environment-friendly fuels, such as compressed natural gas (CNG), liquid natural gas (LNG) and liquid petroleum gas (LPG) or clean propulsive systems (electric or hybrid buses), there is also a significant number of buses with diesel engines. In fact, according to the International Organization for Public Transport (UITP) report published in 2011, almost $95 \%$ of public transport in Europe use Diesel fuel [2]. For this reason, the reduction of their PM and $\mathrm{NO}_{\mathrm{x}}$ emissions is beneficial to reduce pollution in cities, being able to be reached if oxygenated fuels are used as one of the ways.

Although the most used renewable oxygenated diesel fuels are fatty acid methyl ester (FAME) from vegetable oils or animal fats, commonly known as biodiesel fuel, the ethanol-diesel (ED) fuel blends have nonnegligible advantages. The ED fuel blends are more efficient than biodiesel fuels for reducing particulate matter (PM) emissions, in mass or number of particles [3], though in some transient process tested, a slightly higher number of particles emission, with a small diameter, have been measured [4]. Besides that, when the ED fuel blends are used, $\mathrm{NO}_{\mathrm{x}}$ emissions increased under transient processes [5] such as the engine start [6] or certification cycles [7].

One of the most critical problems is the need to modify the fuel reservoir, and the supplying nozzle restricts the use of ED fuel blend only in captive fleets $[8,9]$.

Altitude can modify the effect of the ED fuel blend on emissions. Gómez et al. (2016) [10] showed that the negative effect of ethanol on $\mathrm{NO}_{\mathrm{x}}$ emissions and the positive effect on PM are both attenuated by the altitude. Other authors also came to the same conclusion under steady state engine tests [11]. However, none references can be found focused on the study of the combined effect of altitude under transient sequences when ED fuel blend is used.

Several works have demonstrated that tests following predefined cycles produce very different results compared to real-world driving condition tests [12-15]. Currently, the Euro VI and the US 2010 restrict $\mathrm{NO}_{\mathrm{x}}$ and $\mathrm{PM}$ emissions produced by new vehicles, in Europe and USA respectively [16]. Moreover, these standards include new requirements for vehicle testing such as the following cycles: World Harmonized Stationary Cycle (WHSC), World Harmonized Transient Cycle (WHTC),

\footnotetext{
* Corresponding author

E-mail address: mariacarmen.mata@uclm.es (C. Mata).
} 
off-cycle vehicle testing and in-use vehicle testing. All these tests must be conducted with Portable Emissions Measurement Systems (PEMS) for measuring pollutant emissions [17]. The denominated in-service conformity testing, include tests under urban and extra-urban driving conditions and under express way conduction, all defined according to the Regulation (EC) 582/2011 [16].

Commonly, the analysis of vehicle emissions produced under mentioned above test cycles or simply under real-world driving conditions is represented versus time, or the distance traveled for the whole cycle or test [18]. However, knowing those transient sequences with more contribution on total emissions is also important for understanding the real-world transportation to establish correction measurements for reducing emissions. Among the different transient sequences of a vehicle movement, different authors have identified the acceleration processes as the most contributors to the total emissions of heavy-duty vehicles such as buses $[6,12,19]$.

The main objective of this work was to analyze the effect produced using an ethanol-diesel fuel blend on both $\mathrm{NO}_{\mathrm{x}}$ emissions and particle size distributions (total particle number concentration and geometrical mean diameter) under urban driving condition tests along urban routes, with similar buses at different cities, both located at different altitudes. The analysis of results has been mainly focused on the acceleration sequences. Although the study has been carried out within of a narrow range of altitude variation, it could be one of the few works with a novel statement of the problem.

\section{Experimental setup}

\subsection{Vehicles}

Two urban buses (with comparable mileage and without exhaust gas recirculation nor after-treatment devices) were used for testing and provided by urban bus fleets. At Ciudad Real city was tested an IVECO Europolis bus (denoted as IV) and at Sevilla city was tested a Renault bus, (denoted as RE). Both are Spanish cities. Table 1 shows the main technical specifications of each bus used for testing.

\subsection{Instrumentation}

An HORIBA OBS 1300 gas analyzer was used for the measurement of the relative fuel-air ratio, $\mathrm{NO}_{\mathrm{x}}$ emissions, and ambient conditions whereas a TSI Engine Exhaust Particle Sizer (EEPS) spectrometer was

Table 1

Technical specifications of test buses.

\begin{tabular}{lll}
\hline & IVECO Europolis bus (IV) & Renault city bus (RE) \\
\hline Engine & $\begin{array}{l}\text { Diesel turbocharged with } \\
\text { after-cooler. FIAT D-8060 }\end{array}$ & $\begin{array}{l}\text { Diesel turbocharged with } \\
\text { after-cooler. V8 F2B }\end{array}$ \\
& 45 & \\
Cylinder & 6 in-line & 6 in-line \\
Stroke & 4 & 4 \\
Injection & Direct injection (single & Direct injection (single \\
& injection and advanced & injection and advanced \\
start of injection) & start of injection) \\
Injection system & Rotary pump & Rotary pump \\
Speed range & $500-2700 \mathrm{rpm}$ & $600-2700 \mathrm{rpm}$ \\
Swept volume & $5861 \mathrm{~cm}{ }^{3}$ & $7790 \mathrm{~cm}$ \\
Bore/stroke & $104 \mathrm{~mm} / 115 \mathrm{~mm}$ & $115 \mathrm{~mm} / 125 \mathrm{~mm}$ \\
Compression ratio & $17: 1$ & $18: 1$ \\
Maximum power & $152 \mathrm{~kW}$ at $2700 \mathrm{rpm}$ at $2050 \mathrm{rpm}$ \\
Maximum torque & $670 \mathrm{Nm}$ at $1400 \mathrm{rpm}$ & $1100 \mathrm{Nm}$ at $1000 \mathrm{rpm}$ \\
Transmission & ZF $4 \mathrm{HP} 502 \mathrm{C}$ automatic & VOITH D864.3 automatic \\
Date of & 1999 & 1999 \\
$\quad$ manufacturing & & \\
Weight & $9932 \mathrm{~kg}$ & $12700 \mathrm{~kg}$ \\
Length & $9 \mathrm{~m}$ & $10 \mathrm{~m}$ \\
Emissions Normative & EURO II & EURO II \\
\hline & &
\end{tabular}

used to measure the particle size distributions in transient conditions. The vehicle velocity and its position were determined using a global positioning system (GPS) and an inertial sensor. The sampling frequency was $1 \mathrm{~Hz}$ in all devices.

The EEPS was coupled to a rotating disk (RD) diluter model MD19$2 \mathrm{E}$, as primary dilutor, and an air supply-thermal conditioner model ASET15-1 with an evaporating tube, as secondary dilutor. Following the procedure described by Gómez et al. (2016) [10], a total dilution factor $\mathrm{DF}_{\text {tot }}=217.5$ was used for testing.

The accuracy of the main experimental parameters is also noted in Gómez et al. (2016) [10]. A procedure presented by Arregle et al. (2006) [20] was used for synchronizing the different signal profiles registered. Fig. 1 shows the scheme of the experimental facilities used for on-board measurements in both buses.

\subsection{Test circuits}

Table 2 shows the main characteristic parameters of routes selected for testing in each city. Both circuits mostly run through the center of the cities, for this reason, both circuits were also characterized by low mean velocities (in some parts limited to $50 \mathrm{~km} / \mathrm{h}$ ). In Ciudad Real city, there are many stops, but a part of them are not used by travelers (about half). The authors use cycles whose distribution of accumulated time by category were similar to those in Armas et al. (2012) [6]. The altitude profiles are almost constant along the whole routes.

\subsection{Fuels tested}

Two fuels were used: a) a low sulfur diesel fuel used as the reference (D), and b) an ethanol-diesel blend (ED) made with the reference diesel fuel and $7.7 \% \mathrm{v} / \mathrm{v}$ of ethanol, supplied by Abengoa Bioenergy Corporation. This ethanol content ensures the stability of the blend in a wide temperature range [21]. The main properties of the tested fuels are presented in Table 3.

\subsection{Experimental procedure}

Data collection, from each fuel and bus, was registered throughout the route under real passenger transportation, at the same hour over the five working days of the week, with similar traffic conditions. In both buses, the air conditioning system was disconnected. Moreover, to establish the most comparable test scenario, tests were also carried out under comparable temperature and humidity conditions (approx. $25^{\circ} \mathrm{C}$ y $30 \%)$.

Armas et al. (2012) [6] describe the methodology used for dividing test cycles into categories and classifying them as follows: a) Idle (when the vehicle is stopped, and the engine works in idle); b) Acceleration; c) Deceleration with fuel consumption and d) Deceleration without fuel consumption. As an example, Fig. 2 shows a schematic representation of different categories identified in part of a cycle with IV bus. In this case, the time evolution of velocity speed and Fr is presented. This figure proceeds from Armas et al. (2012) [6].

In the present work, only the analysis of those events included in the acceleration category have been studied. There are mainly three possible situations associated with the acceleration processes: a) acceleration coming from idle, b) acceleration coming from deceleration with fuel consumption and c) acceleration coming from deceleration without fuel consumption [22]. However, the comparison between b) and c) sequences (even separately) is difficult because the first second of these sequences can start at multiple initial velocities. This makes difficult to find enough sequences, with similar initial velocities for both buses and fuels, under established routes in a city. For this reason, in this work, only acceleration sequences coming from idle are studied.

Moreover, time analysis of this kind of acceleration sequences makes possible the comparison in two different scenarios: a) vehicles follow similar time profiles of relative fuel-air ratio and b) vehicles 


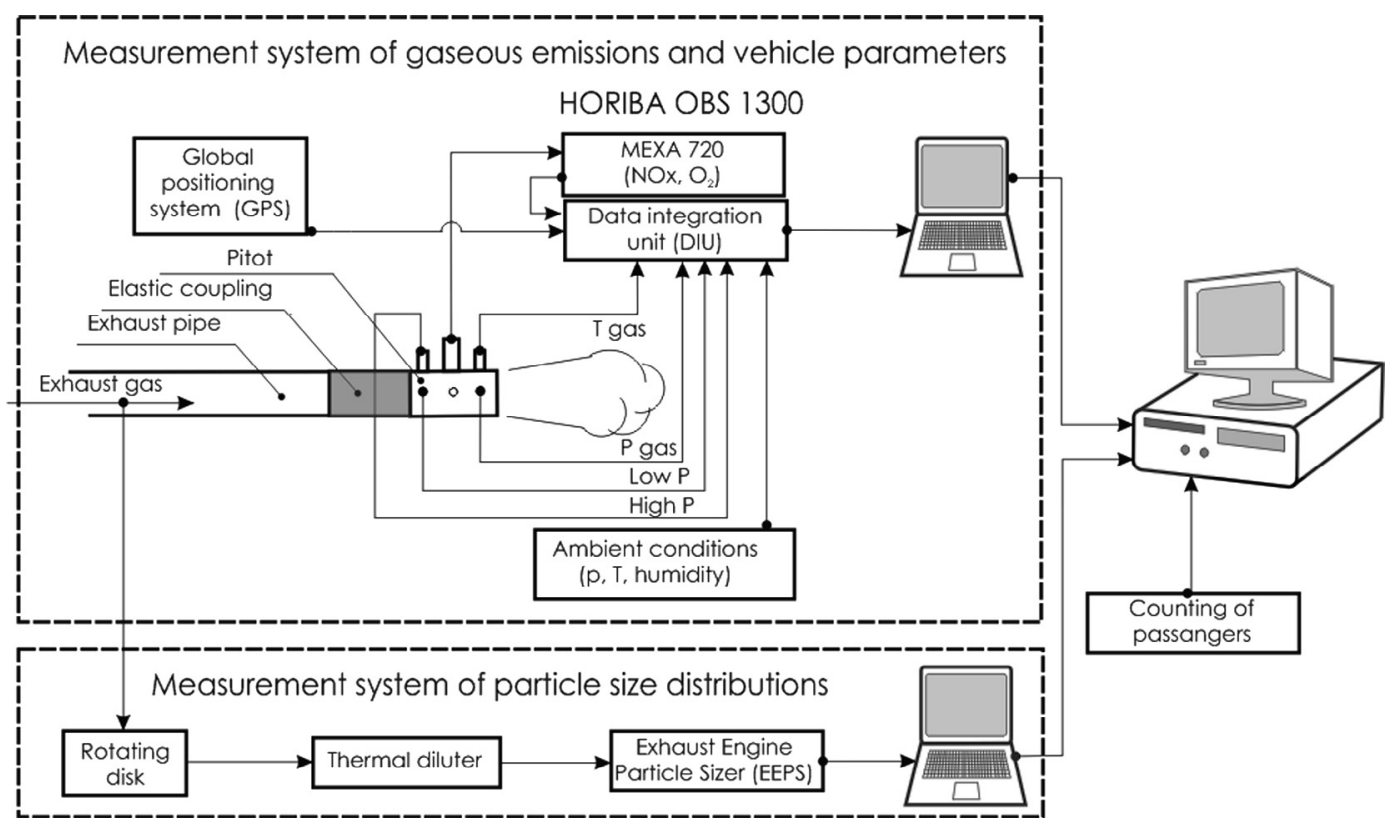

Fig. 1. Scheme of the experimental facilities for measuring gas emissions and particle size distributions.

Table 2

Main specifications of the city routes tested.

\begin{tabular}{lll}
\hline & IVECO Europolis bus (IV) & Renault city bus (RE) \\
\hline City & Ciudad Real (Spain) & Sevilla (Spain) \\
Route number & 1 & 34 \\
Altitude & $650 \mathrm{~m}$ & $10 \mathrm{~m}$ \\
Length & $14.5 \mathrm{~km}$ & $13 \mathrm{~km}$ \\
Journey time & $1 \mathrm{~h}$ & $1 \mathrm{~h}$ \\
Stops for passengers & 67 & 35 \\
Traffic lights & 31 & 21 \\
\end{tabular}

Table 3

Fuel properties.

\begin{tabular}{lll}
\hline & $\mathrm{D}$ & $\mathrm{ED}$ \\
\hline Density at $15^{\circ} \mathrm{C}\left(\mathrm{kg} / \mathrm{m}^{3}\right)$ & 835 & 831 \\
Kinematic viscosity at $40{ }^{\circ} \mathrm{C}(\mathrm{cSt})$ & 2.72 & 2.41 \\
High heating value $(\mathrm{MJ} / \mathrm{kg})$ & 45.54 & 43.82 \\
Low heating value $(\mathrm{MJ} / \mathrm{kg})$ & 42.61 & 40.86 \\
$\% \mathrm{C}$ (by weight) & 86.13 & 83.63 \\
$\% \mathrm{H}$ (by weight) & 13.87 & 13.82 \\
$\% \mathrm{O}$ (by weight) & 0.00 & 2.55 \\
$\% \mathrm{H} \mathrm{O}^{\mathrm{O}}$ (by weight) & 0.0057 & 0.0240 \\
$\% \mathrm{~S}$ (by weight) & 0.0010 & 0.0008 \\
$\mathrm{C} / \mathrm{H}$ mass ratio & 6.209 & 6.051 \\
Stoichiometric fuel-air ratio & $1 / 14.67$ & $1 / 14.25$ \\
Molecular weight $(\mathrm{g} / \mathrm{mol})$ & 211.7 & 167.5 \\
Cetane number & 52.0 & 48.7 \\
Enthalpy of vaporization $(\mathrm{kJ} / \mathrm{kg})$ & 242.8 & 285.0 \\
\hline
\end{tabular}

follow similar time profiles of velocity. The reason why these two scenarios have been contrasting is due to the different results obtained by Armas et al. (2012) [6] when sequences from different initial velocities were studied.

In all cases studied, the time interval analyzed was $6 \mathrm{~s}$ for each sequence and it has been chosen according to three reasons:

a) It is the most common sequence registered during the cycles. Fig. 3 shows, for example, the distribution of the acceleration sequences coming from idle, over the whole time used in a cycle traveled by the IV bus in Ciudad Real city using D fuel.

b) Wang et al. (2011) [12] show that short in time (aggressive) acceleration processes have more contribution to emissions than long in time (less aggressive) ones.

c) Armas et al. (2013) [23] show that, after the third or fourth second, once the acceleration has begun (approximately the instant when values of the relative fuel-air ratio (Fr) reaches the maximum value), $\mathrm{PM}$ emission decreases.

The mean values presented in the results were obtained using second by second data from 20 sequences.

\subsection{Parameters studied}

Values of the relative fuel-air ratio (Fr) and vehicle velocity (Vv) have been considered as characteristic vehicle parameters. In all cases, ambient conditions were registered and were the same in all situations. $\mathrm{NO}_{\mathrm{x}}$ concentration (in ppm) and mass flow rate emissions (in $\mathrm{g} / \mathrm{s}$ ) have been studied.

Total particle number concentration (PC) and geometrical mean diameter $\left(d_{g}\right)$ were calculated from measured particle size distributions as described in Armas et al. (2011) [22]. PC was determined only counting those particles with diameter higher than $23 \mathrm{~nm}$ as states the Particle Measurement Program (PMP) [24].

\section{Results and discussion}

3.1. Time analysis of acceleration sequences (A). Comparison with similar time profiles of the relative fuel-air ratio $(\mathrm{Fr})$

Fig. 4a shows the time evolution of Fr and Vv while Fig. 4b shows the time evolution of $\mathrm{NO}_{\mathrm{x}}$ concentration (ppm) and $\mathrm{NO}_{\mathrm{x}}$ emissions mass flow rate $(\mathrm{g} / \mathrm{s})$ from both buses and fuels tested.

Although the Fr time profiles were similar independently of the vehicle and location tested, velocity profiles were different. Velocity profiles from the RE bus have greater positive slope compared to velocity profile from IV bus. This behavior can be explained through the ratio vehicle weight/engine displacement. According to the information presented in Table 1, the RE bus must drag $1630 \mathrm{~kg}$ of weight per liter of engine displacement while the IV bus must drag $1694 \mathrm{~kg}$ per liter of engine displacement.

However, the Fr time profiles between fuels at each bus were practically the same. This behavior allows the comparison of fuel effect 


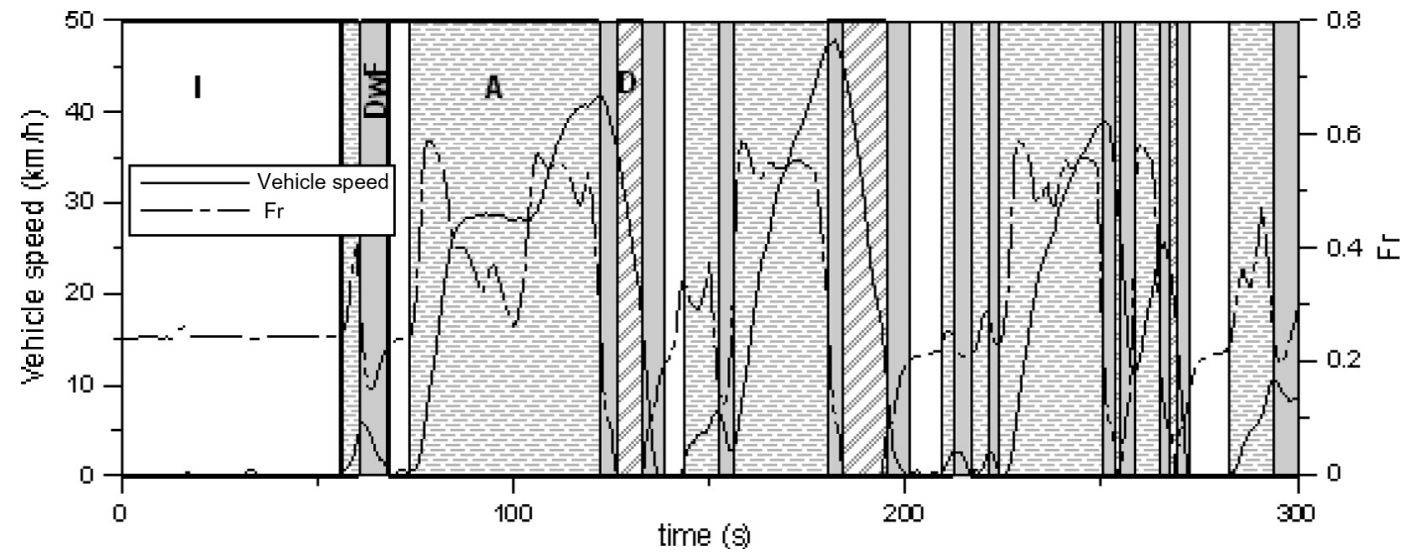

Fig. 2. Categories identified in part of a cycle [6].

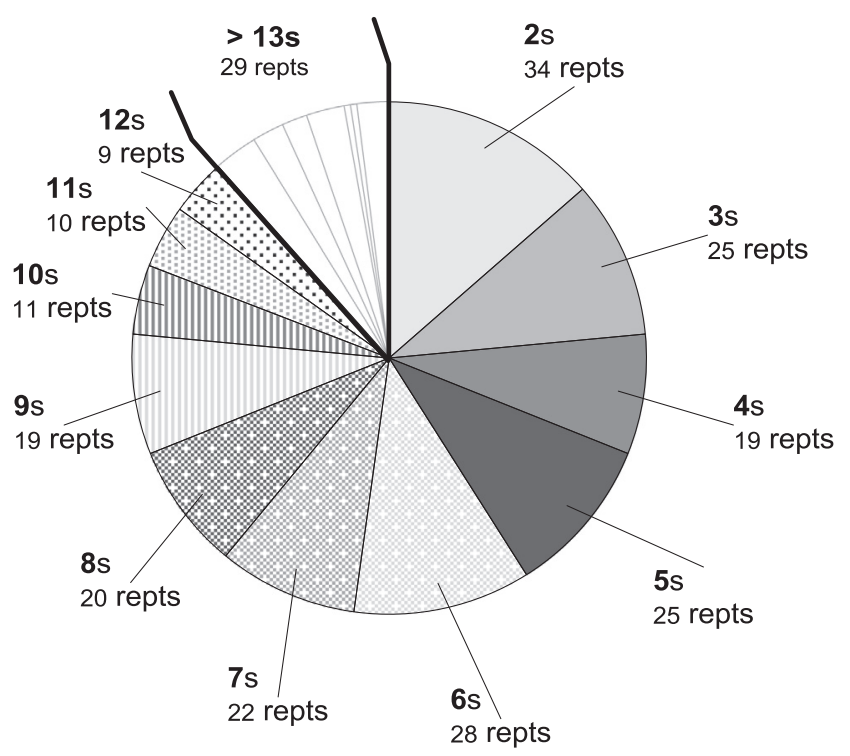

Fig. 3. Time distribution and number of repetitions (repts) of the acceleration sequences coming from idle along the driving route.

with each bus.

Although the Fr profiles between vehicles and fuels were similar, $\mathrm{NO}_{\mathrm{x}}$ concentrations from ED fuel were lower compared to diesel fuel when the IV bus was tested, and it was higher when the RE bus was

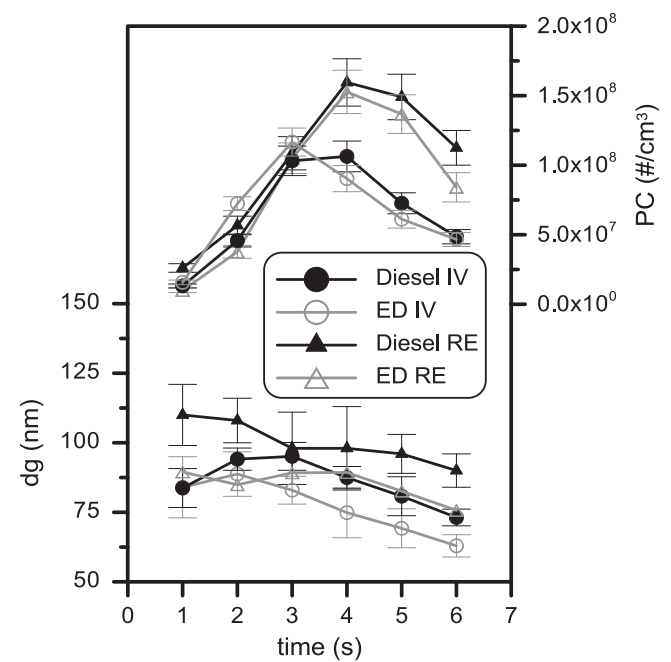

Fig. 5. Particle concentration and geometrical mean diameter of particles measured under acceleration sequence A. Case of comparison: similar Fr profiles between buses.

tested. In both case, the difference $(\sim 7 \%)$ between $\mathrm{NO}_{\mathrm{x}}$ concentrations produced by fuels, in both vehicles, was almost constant along the sequence.

For explaining the effect of fuels on $\mathrm{NO}_{\mathrm{x}}$ concentrations produced by each bus, it is necessary to consider the following factors:

a) The Fr profiles from both buses and fuels were similar. When the Fr
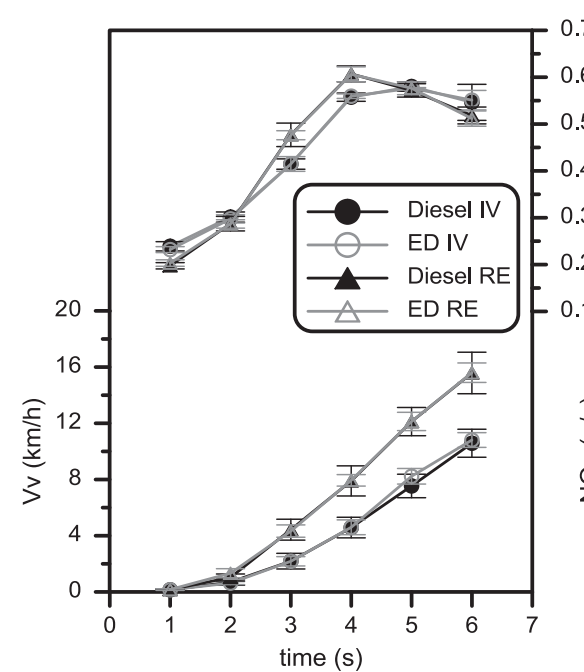

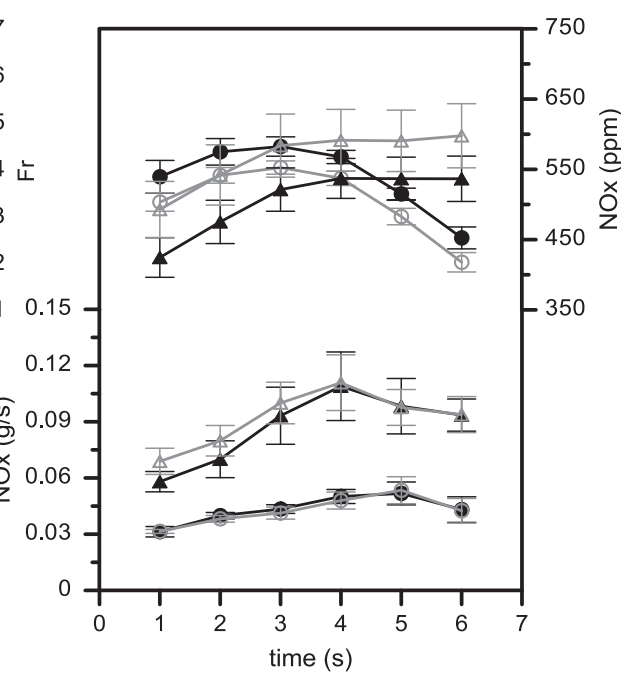

Fig. 4. a) Relative fuel-air ratio (Fr) and Vehicle velocity $(\mathrm{Vv})$ profiles and $\mathrm{b}$ ) Concentration and NOx emission mass flow rate profiles, from sequence A. Case of comparison: similar Fr profiles between buses. 

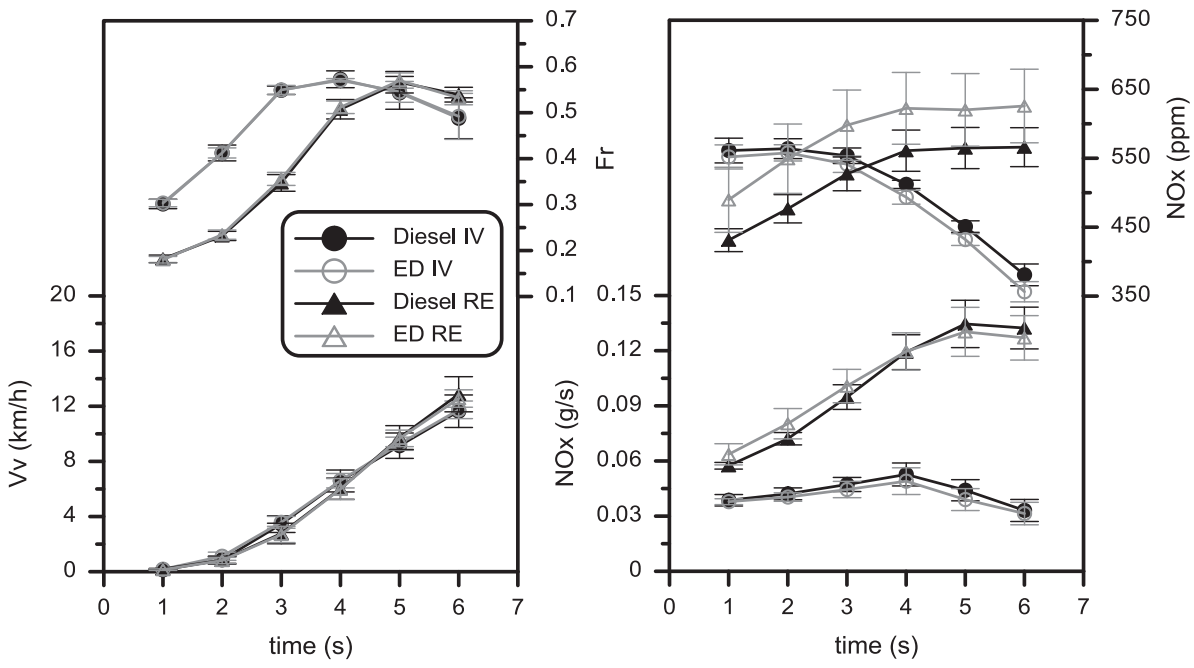

Fig. 6. a) Relative fuel-air ratio (Fr) and Vehicle velocity (Vv) profiles and b) Concentration and NOx emission mass flow rate profiles, from sequence A. Case of comparison: similar Vv profiles between buses.

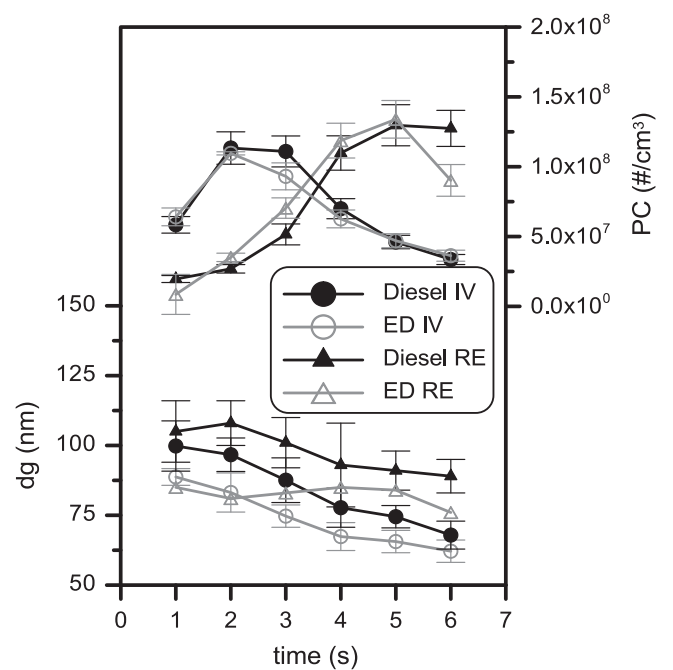

Fig. 7. a) Particle concentration and b) geometrical mean diameter obtained during sequence A with similar velocity profiles A.

profiles are similar the difference in emissions is mainly produced by the fuel properties [25].

b) The compression ratios of the engines installed on the buses. The engine compression ratio of the IV bus tested at Ciudad Real city is higher (see Table 1). This factor would lead to a higher adiabatic flame temperature inside the engine combustion chamber, facilitating this way the $\mathrm{NO}_{\mathrm{x}}$ formation $[21,26]$.

c) The oxygen availability inside the engine combustion chamber of each bus. The oxygen availability is related to the test location. Ciudad Real city, where the IV bus was tested, is located $\sim 630 \mathrm{~m}$ above sea level, while Sevilla city, where the RE bus was tested, is located near the sea level. As higher the altitude is lower the oxygen supply in the air. Below presence of oxygen in the flame leads to a lower $\mathrm{NO}_{\mathrm{x}}$ formation $[26,27]$.

d) The cooling effect inside the combustion chamber of the engine produced by the enthalpy of vaporization of fuels. The higher enthalpy of vaporization of ED fuel blend reduces the adiabatic flame temperature and leads to the increase of ignition delay. By the one hand, the cooling effect of ED fuel blend reduces the NOx formation due to the reduction of the adiabatic flame temperature itself [28]. By the other hand, the cooling effect also would lead to the increase of the ignition delay. If this delay produces a combustion process beyond the in-cylinder top dead center (TDC), then the combustion occurs with additional progressive reduction of adiabatic flame temperature. In these conditions, the enthalpy of fuel vaporization leads to the decrease of $\mathrm{NO}_{\mathrm{x}}$ emission.

According to the factors described above, the lower $\mathrm{NO}_{\mathrm{x}}$ concentration produced by the ED fuel blend when the IV bus was tested at Ciudad Real city, can be explained as follows: the higher enthalpy of vaporization of ED fuel and its cooling effect, combined with the lower oxygen availability at altitude, lead to a decrease in $\mathrm{NO}_{\mathrm{x}}$ concentration, even when the engine compression ratio of IV bus is higher than the engine compression ratio of the RE bus. However, the opposite happens with the RE bus. In this case, the lower altitude leads to a higher oxygen availability inside the engine combustion chamber that, together with the oxygen content of ED fuel blend, produced higher $\mathrm{NO}_{\mathrm{x}}$ concentration. This occurred even when the engine of the RE bus has a lower compression ratio, and the ED fuel blend has a higher enthalpy of vaporization.

However, when $\mathrm{NO}_{\mathrm{x}}$ emission mass flow rates are compared, they are similar between fuels along the time analyzed and different between buses. The difference of $\mathrm{NO}_{\mathrm{x}}$ mass flow rates between buses can be explained by the difference of the bus engine displacement. The RE bus has an engine with a displaced volume 2 liters larger than the displacement of the IV bus engine. More displacement means more quantity of gas displaced by the engine.

Fig. 5 shows second by second evolution of the concentration and geometrical mean diameter of particles emitted by buses with both fuels under the acceleration sequence.

As can be seen in Fig. 5, particle concentration followed time profiles similar to the time profiles of Fr (see Fig. 4a). The maximum concentration of particles emitted is reached around the 4th second, matching with maximum Fr. Particle concentration increases directly proportional respect to the increase of Fr. As lower the oxygen concentration in the air as higher the particle concentration. Compared to diesel fuel, in both buses, particle concentration produced by ED fuel is lower. This behavior is known: the lower quantity of aromatic compounds and the presence of molecular oxygen in ED fuel blend (incorporated through the ethanol added) lead to a cleaner combustion process and explain the registered particle concentrations.

Geometrical mean diameter varied between 60 and $120 \mathrm{~nm}$ independently of the bus or fuel tested. In both buses, mean diameter of particles apparently decreases with ED fuel blend. Similar results have been reported by Lapuerta et al. (2008) [29], Di et al. (2009) [30] and Armas et al. (2013) [23]. Once again, a cleaner combustion process leads to lower particle size. However, an unclear trend has been observed respect to the time evolution of the Fr. 


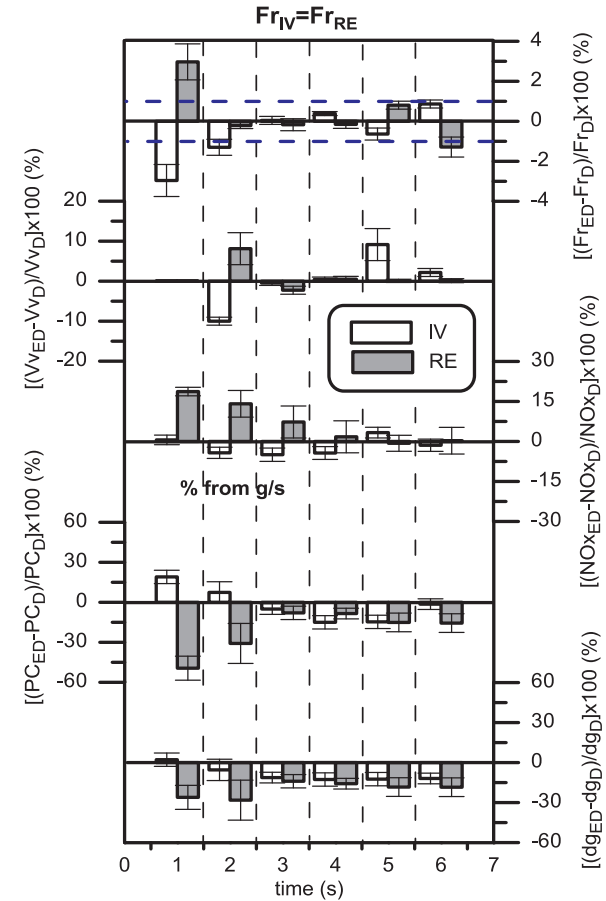

(a)



(b)

\subsection{Time analysis under acceleration sequences (A). Comparison with similar time profiles of vehicle velocity $(\mathrm{Vv})$}

Fig. 6a shows the time evolution of the bus velocity (Vv) and the relative fuel-air ratio (Fr) with both fuels tested, compared at similar vehicle velocity time profiles.

Under similar velocity profiles, the Fr profiles of both buses are very different. The IV bus demanded higher Fr along the first four seconds under acceleration sequences in comparison with the RE bus. Once again, this behavior can be explained through the ratio vehicle weight/ engine displacement. In this case, the vehicle IV bus needed higher Fr due to the higher relative weight compared to the RE bus. In each bus, the Fr profiles were similar between fuels.

Fig. $6 \mathrm{~b}$ shows the time evolution of concentration and mass flow rates of $\mathrm{NO}_{\mathrm{x}}$ emissions with both fuels and buses. As occurred and was analyzed in the previous sub-section, once the Fr profiles between fuels were similar in each bus, the analysis and justification of results is the same.

Fig. 7 shows particle concentration and geometrical mean diameter. In this case, although the time profiles of particle concentration followed the pattern of the Fr, the maximum of particle concentration did not match in time.

In IV bus the maximum of particle concentration was registered slightly before the Fr maximum. This could be explained due to the lower oxygen content at altitude together with the delayed response of the turbocharger which leads to the local formation of particles during the combustion process.

Geometrical mean diameter followed similar trends to those seen in the previous sub-section. In this case, the range of variation was slightly narrower (between 60 and $100 \mathrm{~nm}$ ).

\subsection{Summary of results}

Fig. 8 shows a summary of the effect of ED fuel blend, second by second, along the acceleration sequences in each bus tested under both conditions of comparison a) $\mathrm{Fr}_{\mathrm{IV}}=\mathrm{Fr}_{\mathrm{RE}}$ and b) $\mathrm{VV}_{\mathrm{IV}}=\mathrm{VV}_{\mathrm{RE}}$. As can be seen, similar Fr were considered when the difference was lower than $2.5 \%$ while similar vehicle velocities were considered when the difference was lower than $5 \%$. These ranges are presented in the figures with dashed lines.

According to the summary presented in Fig. 8a (under comparison condition $\mathrm{Fr}_{\mathrm{IV}}=\mathrm{Fr}_{\mathrm{RE}}$ ) it can be appreciated that the ED fuel blend has positive effect on reduction of both $\mathrm{NO}_{\mathrm{x}}$ emission and particle concentration in both type of buses and both cities (located at different altitude) from the 3rd to the 6th second of the acceleration sequences studied. However, an apparent reduction of particle size $(\sim 15 \%)$ is observed along the whole sequence time when the ED fuel blend was used independently of the bus testing.

During the first 2-3 s of the sequence, $\mathrm{NO}_{\mathrm{x}}$-particle trade-off is observed. However, it is different in each bus tested. In IV bus reductions of $\mathrm{NO}_{\mathrm{x}}$ emissions $(\sim 5-7 \%)$ were observed while increases of particle concentration $(\sim 7-15 \%)$ were registered. At the beginning of the transient sequence, the reduced concentration of the oxygen in the air (due to the higher altitude) leads to these results. In RE bus, an inverse trade-off was observed at the beginning of the transient sequence. An increase of $\mathrm{NO}_{\mathrm{x}}$ emissions $(\sim 15 \%)$ was observed while reductions of particle concentration $(\sim 30-45 \%)$ were registered.

In Fig. $8 b$ (under comparison condition $\mathrm{Vv}_{\mathrm{IV}}=\mathrm{Vv}_{\mathrm{RE}}$ ) the effect of ED fuel blend on particle concentration changes depending on the instant study. In any case, significant reductions were registered with the RE bus (tested at lower altitude) at the beginning and the end of the transition. However, in between of both instants, negligible differences were registered. With the IV bus reductions of particle concentration were registered in the middle of the transition (seconds 3 and 4). $\mathrm{NO}_{\mathrm{x}}$ emissions were reduced in both buses although the most important reduction was observed at the end of the tested sequence. In summary, facts described at the beginning of this section affect different on $\mathrm{NO}_{\mathrm{x}}$ emissions and particle concentration depending on the altitude and the instant of the sequence.

Geometrical mean diameter was reduced with ED fuel blend independently of both, the bus tested and the instant of the sequence. Also, this result has been observed when other types of sequence are analyzed $[4,10]$. 


\section{Conclusions}

The main conclusions of this work are the following:

- The effect of ED fuel on $\mathrm{NO}_{\mathrm{x}}$ concentrations, registered under acceleration transitions, depends on the vehicle configuration, the altitude of vehicle operation and depends on the type of the acceleration transition.

- At $650 \mathrm{~m}$ of altitude, the $\mathrm{NO}_{\mathrm{x}}$ concentrations decreased when ED fuel is used due to the combined effect of a) the cooling effect of its higher enthalpy of vaporization and b) the lower oxygen availability at higher altitude. This occurred although the compression ratio of the engine is greater compared to the RE bus. However, under transitions with similar velocity profiles and with more aggressive Fr increase, the effect of ED fuel is not evident. In this last case, the effect Fr increase is more significant than the cooling effect of its enthalpy of vaporization.

- At sea level, $\mathrm{NO}_{\mathrm{x}}$ concentrations increased as consequence of the higher oxygen availability at the lower altitude. This occurred although the compression ratio of the engine is lower compared to the IV bus and the cooling effect of the ED fuel. This behavior was observed independently of the type of transition (similar velocity or similar Fr).

- With similar velocity profiles, particle concentrations were similar with both fuels and both buses. However, with similar Fr profiles, the positive effect of the ED fuel on particle concentration is more noticeable on the RE bus than on the IV bus. This effect is due to the higher oxygen availability at low altitude.

- Fuel comparison under transient sequences, when vehicle velocity is increasing, must be done at similar relative fuel air ratio profiles instead of at similar vehicle velocity profiles. Differences in relative fuel air ratio masks the effects of fuel properties.

- Particle mean diameter is reduced with ED fuel and both buses, it is this reduction greater when the RE bus was tested. Here again, the oxygen availability at low altitude has the responsibility of this reduction.

As the summary, when the ED fuel is used in buses (with engines equipped without variable geometry turbocharger), the effect of fuel is different. The altitude clearly modifies the trade-off $\mathrm{NO}_{\mathrm{x}}$-particles even when the ED fuel is used.

\section{Acknowledgements}

The authors wish to thank the financial support provided by a) the Castilla-La Mancha government (research project PAI 06-160, COMEDIA) and b) the Spanish CDTI (research project CENIT 20071031, I+ DEA). Authors also wish to thank the technical support provided by the companies: ABENGOA Bioenergy S.A., AISA S.A., TUSSAM and O2Diesel S.A.

\section{References}

[1] Wang J, Storey J, Domingo N, Huff S, Thomas J, West B. Studies of diesel engine particle emissions during transient operations using an engine exhaust particle sizer. Aerosol Sci Technol 2006;40(11):1002-15.

[2] UITP. International Association of Public Transport. Towards low/zero-carbon urban mobility in Europe. UITP position paper, http://www.uitp.org/sites/default/ files/cck-focus-papers-files/FPNov2011.pdf [accessed 11.01.17].
[3] Geng P, Cao E, Tan Q, Wei L, Effects of alternative fuels on the combustion characteristics and emission products from diesel engines: a review. Renewable Sustainable Energy Rev 2017;71:523-34.

[4] Armas O, Gómez A, Mata C, Ramos A. Particles emitted during the stops of an urban bus fuelled with ethanol-biodiesel-diesel blends. Urban Clim 2012;2:43-54.

[5] Hansen AC, Zhang Q, Lyne PWL. Ethanol-diesel fuel blends-a review. Bioresour Technol 2005;96:277-85.

[6] Armas O, Lapuerta M, Mata C. Methodology for the analysis of pollutant emissions from a city bus. Meas Sci Technol 2012;23:045302.

[7] Armas O, García-Contreras R, Ramos A. Pollutant emissions from New European Driving Cycle with ethanol and butanol diesel blends. Fuel Process Technol 2014;122:64-71.

[8] McCormick RL, Parish R. Technical barriers to the use of ethanol in diesel fuel. Golden, Colorado: National Renewable Energy Laboratory; 2001.

[9] Armas O, Lapuerta M, Mata C, Pérez D. Online emissions from a vibrating roller using an ethanol-diesel blend during a railway construction. Energy Fuels 2009;23:2989-96.

[10] Gómez A, Mata C, Armas O. Effect of ethanol-diesel fuel blend on diesel engine emissions produced by different bus fleets. J Energy Eng 2016;142(2):E4015003.

[11] Liu S, Shen L, Bi Y, Lei J. Effects of altitude and fuel oxygen content on the performance of a high pressure common rail diesel engine. Fuel 2014;118:243-9.

[12] Wang AJ, Ge YS, Tan JW, Fu ML, Shah AN, Ding Y, et al. On-road pollutant emission and fuel consumption characteristics of buses in Beijing. J Environ Sci 2011;23(3):419-26.

[13] Liu Z, Ge Y, Johnson KC, Shah AN, Tan J, Wang C, et al. Real-world operation conditions and on-road emissions of Beijing diesel buses measured by using portable emission measurement system and electric low-pressure impactor. Sci Total Environ 2011;409:1476-80.

[14] Mamakos A, Bonnel P, Perujo A, Carriero M. Assessment of portable emission measurement systems (PEMS) for heavy-duty diesel engines with respect to particulate matter. J Aerosol Sci 2013;57:54-70.

[15] Suarez-Bertoa R, Mendoza-Villafuerte P, Bonnel P, Lilova V, Hill L, Perujo A, et al On-road measurement of NH3 and N2O emissions from a Euro V heavy-duty vehicle. Atmos Environ 2016;139:167-75.

[16] European Commission. Commission regulation (EU) No 582/2011 of 25 May 2011 implementing and amending regulation (EC) No 595/2009 of the European Parliament and of the council with respect to emissions from heavy duty vehicles (Euro VI) and amending annexes I and III to directive 2007/46/EC of the European Parliament and of the council. Official J Eur Union 2011:L 167:1-168.

[17] Giechaskiel B, Vlachos T, Riccobono F, Forni F, Colombo R, Montigny F, et al Implementation of Portable Emissions Measurement Systems (PEMS) for the Realdriving Emissions (RDE) regulation in Europe. J Vis Exp 2016;118:54753.

[18] Ropkins K, Beebe J, Li H, Daham B, Tate J, Bell M, et al. Real-world vehicle exhaust emissions monitoring: review and critical discussion. Crit Rev Environ Sci Technol 2009;39:79-152.

[19] Sandhu GS, Frey HC, Bartelt-Hunt S, Jones E. In-use measurement of the activity, fuel use, and emissions of front- loader refuse trucks. Atmos Environ 2014;92:557-65.

[20] Arregle J, Bermudez V, Serrano JR, Fuentes E. Procedure for engine transient cycle emissions testing on real-time. Exp Therm Fluid Sci 2006;30(5):485-96.

[21] Lapuerta M, Armas O, García-Contreras R. Effect of ethanol on blending stability and diesel engine emissions. Energy Fuels 2009;23:4343-54.

[22] Armas O, Gomez A, Mata C. Methodology for measurement of diesel particle size distributions from a city bus working in real traffic conditions. Meas Sci Technol 2011;22:105404.

[23] Armas O, Gómez A, Mata C, Ramos A. Particle size distributions from a city bus fuelled with ethanol-biodiesel-diesel fuel blends. Fuel 2013;111:393-400.

[24] Rubino L, Bonnel P, Carriero M, Krasenbrink A. Portable Emission Measurement System (PEMS) For heavy duty diesel vehicle PM measurement: the European PM PEMS program. SAE Int J Engines 2010;2(2):660-73.

[25] Xue J, Grift TE, Hansen AC. Effect of biodiesel on engine performances and emissions. Renewable Sustainable Energy Rev 2011;15(2):1098-116.

[26] Can O, Celikten I, Usta N. Effects of ethanol addition on performance and emissions of a turbocharged indirect injection Diesel engine running at different injection pressures. Energy Convers Manage 2004;45:2429-40.

[27] Liu J, Ge Y, Wang X, Hao L, Tan J, Peng Z, et al. On-board measurement of particle numbers and their size distribution from a light-duty diesel vehicle: influences of VSP and altitude. J Environ Sci 2017;57:238-48.

[28] Lapuerta M, Armas O, Agudelo JR, Agudelo AF. Study of altitude effect on internal combustion engines operation. Part 2: diesel engines. Información Tecnológica 2006;17(5):31-41.

[29] Lapuerta M, Armas O, Herreros JM. Emissions from a diesel-bioethanol blend in an automotive diesel engine. Fuel 2008;87:25-31.

[30] Di Y, Cheung CS, Huang Z. Experimental study on particulate emission of a diese engine fueled with blended ethanol-dodecanol-diesel. Aerosol Sci 2009;40:101-12. 